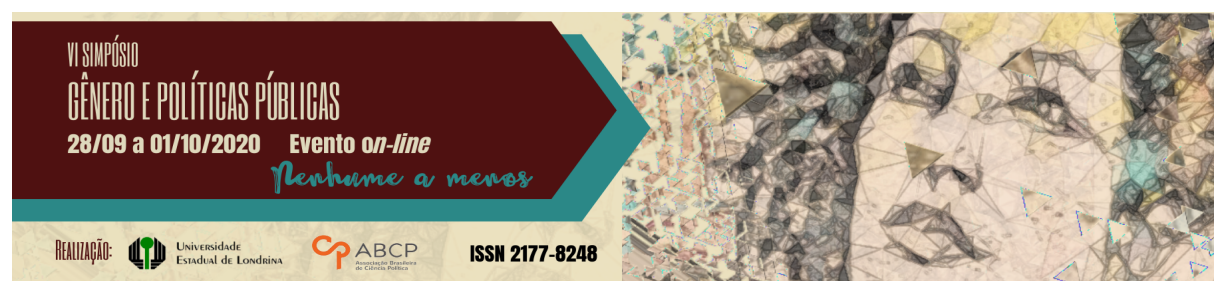

\title{
Mulheres migrantes e desenvolvimento humano: potencialidades de agência
}

\author{
Letícia Zamprônio Salum ${ }^{1}$
}

\section{Resumo}

Este trabalho é uma reflexão acerca das migrações internacionais de mulheres e tem por finalidade compreender o processo migratório das mulheres como liberdade de agência, expansão das capacidades e, $\operatorname{logo}$, o avanço no desenvolvimento humano dessas mulheres. A partir da teoria de Amartya Sen, discute-se a migração como exercício de liberdade e como parte importante do processo de expansão das capacidades das pessoas, o qual possibilita o progresso no desenvolvimento humano. Além disso, embasada por teorias feministas, também se analisa as migrantes são protagonistas do ato migratório e se demonstra a importância disso. Por fim, propõe-se a potencialidade de agência dessas mulheres mesmo enfrentando sistemas interseccionais de opressão.

Palavras-chave: migrações internacionais; desenvolvimento humano; gênero.

\section{Migrant women and human development: potential for agency}

\begin{abstract}
This work is an analysis on the international migration of women and it aims to understand the migratory process of women as freedom of agency, expansion of capacities and, therefore, the advance in the human development of these women. Based on Amartya Sen's theory, migration is understood as an exercise of freedom and as an important part of the process of expanding the capacities of people, which enables progress in human development. In accordance with the feminist theories, it is also analyzed female migrants as
\end{abstract}

\footnotetext{
${ }^{1}$ Mestranda no Programa de Ciências Humanas e Sociais da Universidade Federal do ABC. Graduada em Ciências Sociais pela Universidade Estadual de Londrina em 2012. Contato: leticiazsalum@gmail.com.
}

GT 12 - Gênero, refúgio e migrações 
protagonists of the migratory act and it argues about its importance. Finally, it proposes the potential of agency of these women even facing intersectional systems of oppression.

Keywords: international migration; human development; gender.

\section{Introdução}

As migrações internacionais são constituídas a partir de condições históricas específicas em contextos socioeconômicos particulares (MASSEY et al, 2008). Grande parte da literatura acerca do tema - tal como Massey, Sassen, De Haas, Castles e Miller - compreende que há uma relação entre os movimentos migratórios e o processo de desenvolvimento dos países, principalmente no que concerne aos fatores econômicos e o mercado de trabalho, a economia mundial e os avanços tecnológicos (MASSEY et al, 2008; DE HAAS, 2010; CASTLES, MILLER, 2009; SASSEN, 2010). O fenômeno da migração tem sido estudado e analisado de diversas formas: a partir da experiência do migrante e o direito de migrar, acerca da necessidade de elaboração de políticas públicas para essa população e também sobre as dificuldades das nações em garantirem os direitos dos migrantes, entre outros aspectos (MASSEY et al, 2008; SANTOS et al, 2010; DE HAAS, 2010).

No entanto, muitos desses estudos levavam em conta o homem como figura universal das migrações e retratavam as mulheres como acompanhantes ou dependentes dessa figura masculina. A partir da década de 1980, as pesquisas sobre a migração passaram a observar as mulheres migrantes sob uma nova ótica: a mulher como protagonista da migração. Contestando estudos até então produzidos, Morokvasić (1984) questiona o enfoque dado à figura masculina nos estudos migratórios e enfatiza que as mulheres não desempenham apenas o papel de acompanhante de seu cônjuge e de sua família, mas sim, as mulheres têm papel ativo no ato de migrar. A abordagem de gênero, então, é importante para compreender as nuances e as diferenças no processo migratório de mulheres e homens. É importante salientar que as experiências das mulheres migrantes têm muitas peculiaridades e se 
diferenciam das experiências masculinas, razão pela qual é imprescindível se utilizar perspectivas teóricas feministas que compreendam como os movimentos migratórios das mulheres são estruturados por relações, papéis e hierarquias de gênero (BOYD; GRIECO, 2003).

A partir da compreensão da estrutura social das diferenciações baseadas no gênero, este estudo com enfoque na migração de mulheres busca analisar a questão do desenvolvimento, especialmente do desenvolvimento humano, baseado na teoria de Amartya Sen (2000). Em Sen, é possível se compreender que o desenvolvimento humano se dá a partir da expansão das capacidades das pessoas. E a capacidade de uma pessoa reflete a sua liberdade em escolher como viver a partir das condições e oportunidades existentes. Nessa reflexão, Sen (1993), então, compreende que essa liberdade é uma liberdade de agência, a qual implica que a pessoa tem a oportunidade de avaliar e decidir sobre como exercerá sua liberdade pessoal.

A partir do referencial teórico de Amartya Sen sobre a abordagem das capacidades e o conceito de agência, e de estudos com a compreensão da perspectiva de gênero, busca-se evidenciar neste artigo as potencialidades de avançar no desenvolvimento humano das mulheres migrantes, em termos de ampliação das capacidades e liberdade, a partir da sua liberdade de agência.

\section{Migração e desenvolvimento: apontamentos gerais}

A ligação entre migração e desenvolvimento tem sido evidenciada em vários estudos migratórios, como identificam Santos et al (2010). Estes estudos analisam os fluxos migratórios a partir de diversos aspectos, mas ainda é preciso avançar nas reflexões que compreendam as múltiplas dimensões das migrações a fim de se compreender o fenômeno de modo processual (MASSEY et al, 2008, p. $5)$. 
Nos estudos que compreendem o nexo migração e desenvolvimento, existem em duas perspectivas mais amplas, calcadas na racionalidade: a microeconômica, com uma análise baseada no indivíduo, na família ou no domicílio, e a macroeconômica, com fundamentação a partir da conjuntura dos países de origem e destino (SANTOS et al, 2010, p. 7).

Na perspectiva macroeconômica, entende-se que os movimentos migratórios estão relacionados ao desenvolvimento do capitalismo, à distribuição desigual de mão-de-obra e oferta de trabalho, à procura de mão-de-obra por grandes centros industriais e à busca por melhoria da situação material pelo indivíduo (SANTOS et al, 2010, p.10-1). Assim, supõem a visão dos indivíduos que migram a partir de uma comparação entre o local de origem e o de destino no que concerne aos fatores positivos e negativos - ou de atração e repulsão (os chamados push-pull factors). De modo geral, entende-se que áreas mais desenvolvidas, consideradas mais industrializadas, têm fatores que atraem os migrantes, enquanto locais com pouco desenvolvimento e áreas agrícolas levariam à repulsão dos indivíduos. Além disso, há a seletividade dos indivíduos migrantes por meio de obstáculos intervenientes, como barreiras físicas e leis que restringem os movimentos migratórios (LEE, 1966, p. 51). Com isso, distinguem-se os imigrantes bem-vindos, com determinadas qualidades e atributos individuais, daqueles que não as possuíam, ou seja, não eram estimados como mão-de-obra necessária no país de destino (SANTOS, 2010, p. 10).

No âmbito dessa análise, há ainda a segmentação do mercado de trabalho. Para Piore (1979), a segmentação se deve à existência da hierarquia do mercado de trabalho, a qual está ligada à própria estrutura hierárquica da sociedade. Nesse sentido, as pessoas tendem a aceitar trabalhos dentro do seu nível socioeconômico ou, então, em níveis acima, mais prósperos. Os postos de trabalho nas camadas inferiores dessa hierarquia não são atrativos aos nacionais, então, a mãode-obra migrante supre esse nível hierárquico. A teoria do mercado segmentado caminha pari passu à teoria das escolhas racionais. 
Inclusive, segundo Massey et al, (2008), os trabalhadores nativos atribuem valores negativos às vagas com baixos salários, as quais se tornam oportunidades para estrangeiros, levando-os a reavaliarem riscos e se sentirem confiantes em migrar (MASSEY et al, 2008, p. 33). Essa teoria está dentro, principalmente, da perspectiva microeconômica.

De mais a mais, as perspectivas micro e macroeconômica estão interligadas e, diversos autores acabam utilizando dessas perspectivas conjuntamente. Massey et al (2008), inclusive, expõem que, todos os argumentos já construídos no interior dos estudos migratórios acabam se tornando parte das motivações e justificativas para a existência intensa da migração no mundo globalizado, o que denominam de causação cumulativa, que variados fatores operam em diferentes níveis do processo migratório.

Importante destacar que, em suma, a intensificação dos movimentos migratórios ao avanço do capitalismo, especialmente relacionado à industrialização dada a partir dele (SANTOS, 2010, p. 12). Em “The age of migration", Stephen Castles e Mark J. Miller (2009) corroboram a esse argumento no debate, defendendo que a globalização "levaria a transformações sociais importantes tanto nos países do Sul quanto nos do Norte, proporcionando condições para a expansão e reconfiguração da migração global" (CASTLES; MILLER, 2009, p.50). Além disso, a migração e o desenvolvimento são fenômenos que se relacionam e, em contexto da globalização, acabam por se influenciarem:

Estudos mostram de modo consistente que migrantes internacionais não vêm de lugares pobres e isolados que estão desconectados do mercado mundial, mas de regiões e nações que estão passando por rápidas mudanças e desenvolvimento como um resultado de sua incorporação nas redes globais de comércio, informação e produção. A curto prazo, a migração internacional não provém da falta de 
desenvolvimento econômico, mas do próprio desenvolvimento ${ }^{2}$ (MASSEY et al, 2008, p. 277).

De Haas (2010) observa que existe uma mudança de paradigma científico e na elaboração de políticas que têm se distanciado das teorias clássicas sobre migrações, além de salientar que avaliações diferenciadas sobre a relação recíproca entre migração e desenvolvimento estão intrinsecamente ligadas à conceituação do que de fato se entende por desenvolvimento (DE HAAS, 2010, p. 257). Para De Haas, caso não sejam fomentadas políticas públicas pelos Estados que fortaleçam as instituições sociais, legais, econômicas e políticas, o acesso das pessoas aos serviços básicos e aos mercados que restaurem a confiança nos governos, então, não haverá um terreno fértil para o desenvolvimento. $\mathrm{O}$ mesmo deve ser compreendido à luz das restrições estruturais as quais limitam a vida dos indivíduos, sendo os Estados cruciais na superação dessas condições para um desempenho favorável ao desenvolvimento humano (DE HAAS, 2010, p. 257).

\section{A abordagem das capacidades, o desenvolvimento humano e a agência}

Sendo as migrações um fenômeno intrinsecamente ligado ao desenvolvimento, é possível elaborarmos uma reflexão que compreenda as possibilidades de desenvolvimento de uma outra perspectiva? Assim, este estudo visa deslocar a discussão do desenvolvimento a partir da perspectiva do crescimento econômico dos países de origem e de destino das migrações para pensarmos com base no enfoque do desenvolvimento humano do migrante, a partir da teoria de Amartya Sen.

\footnotetext{
2 No original: "Studies consistently show that international migrants do not come from poor, isolated places that are disconnected from world markets, but from regions and nations that are undergoing rapid change and development as a result of their incorporation into global trade, information, and production networks. In the short run, international migration does not stem from a lack of economic development, but from development itself". Cf. Massey et al, 2008, p. 277.
} 
Essa abordagem teórica e interpretativa da realidade social desloca o foco restrito do debate de uma ótica economicista e amplia o olhar sobre a questão da redução da desigualdade e da pobreza a partir da ênfase nas necessidades das pessoas, como nos ensina o autor:

A principal preocupação é com a qualidade da vida que alguém possa ter. A necessidade de possuir mercadorias para alcançar determinadas condições de vida podem variar bastante de acordo com os aspectos fisiológicos, sociais, culturais, e outras características contingentes [...]. O valor do padrão de vida repousa no viver e não na posse de mercadorias, as quais têm relevância secundária e variável3 (SEN, 1990, p. 34).

Sen (2000) discorre que a expansão das capacidades é primordial para o processo de desenvolvimento, pois é por meio dela que o indivíduo tem condição para o "livre agir", a autonomia, a autodeterminação e o poder de agente (PINHEIRO, 2012, p.14). Em razão disso, o desenvolvimento humano advém da superação das "fontes de privação das liberdades dos indivíduos" (SEN, 2000, p. 33), que podem ser materiais ou econômicas, mas também podem ser políticas, sociais, ou relacionadas ao enfrentamento das mais diversas desigualdades e da pobreza (SEN, 2000, p. 34). Conforme nos explica o próprio autor:

A expansão da liberdade é vista, por essa abordagem, como o principal fim e o principal meio do desenvolvimento. $O$ desenvolvimento consiste na eliminação de privações de liberdade que limitam as escolhas e as oportunidades das pessoas de exercer ponderadamente sua condição de agente. A eliminação de privação de liberdades substanciais, argumenta-se aqui, é constitutiva do desenvolvimento (SEN, 2000, p. 10).

\footnotetext{
${ }^{3}$ No original: "The main issue is the goodness of the life that one can lead. The needs of commodities for any specified achievement of living conditions may vary greatly with various physiological, social, cultural, and other contingent features [...]. The value of the living standard lies in the living and not in the possessing of commodities, which has derivative and varying relevance".
} 
Segundo Sen (2000), a explicação está no fato de que, para promover o desenvolvimento humano e ocorrer a verdadeira superação das desigualdades e da pobreza, é necessário que exista a condição de agente da pessoa:

Embora a prosperidade econômica ajude as pessoas a ter opções mais amplas e a levar uma vida mais gratificante, o mesmo se pode dizer sobre educação, melhores cuidados com a saúde, melhores serviços médicos e outros fatores que influenciam causalmente as liberdades efetivas que as pessoas realmente desfrutam (SEN, 2000, p. 334).

Por isso, o enfoque da abordagem das capacidades compreende que a renda é sim um instrumento para o progresso econômico e desenvolvimento social. Entretanto, a teoria de Sen se preocupa em salientar o papel da agência para mudanças coletivas, com observação da autonomia e também com fundamentação nos direitos humanos (PARR, 2002, p. 7). Nas palavras do autor:

A realização da condição de agente de uma pessoa refere-se à realização dos objetivos e valores que ela tem razão para buscar, estejam eles conectados ou não ao seu próprio bem-estar. Uma pessoa como agente não necessita ser guiada somente por seu próprio bem-estar e a realização da condição de agente refere-se ao seu êxito na busca da totalidade de seus objetivos e finalidades ponderados (SEN, 2008, p. 103).

Com isso, observa-se que a condição de agente e o bem-estar são interdependentes - a busca pelo segundo pode ser objetivo do primeiro, por exemplo (SEN, 2008, p. 104). Por um lado, a teoria sustenta que há a possibilidade de êxito na condição de agente a partir da ocorrência real de um objetivo almejado, independente da ação do indivíduo que o almejou. Entretanto, uma segunda concepção se baseia na participação do indivíduo na ocorrência do objetivo almejado (SEN, 2008, p. 105). 


\section{Migração de mulheres na perspectiva de gênero}

A invisibilidade da mulher migrante e o estereótipo da mulher dependente foram bastante criticados por muitos estudos a partir da década de 1980 (MOROKVASIC, 1984; PESSAR, 1984; BOYD; GRIECO, 2006). Essas autoras salientam a negligência dos estudos no tratamento da mulher como sujeito da migração. Além disso, Boyd e Grieco (2006) ainda observam que a negligência estava relacionada ao fato de que os estudos equacionavam o homem como migrante-padrão, figura da migração, sempre "o migrante", com a omissão do termo homem ou masculino. Enquanto os estudos sobre a migração de mulheres tratavam o fenômeno com termos que caracterizassem a especificidade, como a "migrante mulher", a "migração feminina", entre outros termos.

Os estudos migratórios também negligenciavam a mulher como uma migrante desacompanhada, em deslocamentos em que estivesse sozinha, e em migrações em que ela fosse chefe de família e líder dos movimentos migratórios (MOROKVASIC, 1984). Entretanto, com a crescente e irreversível participação das mulheres nas atividades sociais e a importância da perspectiva de gênero nas análises das Ciências Sociais, o paradigma dos estudos sobre migrações mudaram e começaram a serem problematizados os deslocamentos de mulheres (CASTRO, 2006, p.20).

Morokvasić (1984) também chama a atenção em seu texto para o fato de que as mulheres sempre migraram, embora não fossem contabilizadas nas estatísticas - por serem compreendidas como meras acompanhantes de seus maridos ou por estarem trabalhando em setores que não eram contabilizados economicamente, como atividades domésticas e a prostituição (MOROKVASIĆ, 1984, p. 887). Este estudo além de contextualizar as migrações de mulheres, evidenciando a participação das mulheres nas migrações internacionais, ainda ressalta como a negligência à figura da mulher que migrava era um problema tanto nos estudos migratórios quanto na elaboração de políticas públicas (MOROKVASIC, 1984, p. 888-9). 
Essa condição inferiorizada da mulher passou a ser questionada nos estudos de gênero que, logo, passaram a observar a mulher no contexto das migrações internacionais. Ao passo que acontecia essa abertura conceitual no âmbito dos estudos migratórios à figura da migrante, houve também um aumento da participação das mulheres nos movimentos migratórios, um processo denominado como feminização das migrações. Esse contexto foi importante para que o tema da migração e os papéis e as relações de gênero se tornasse destaque entre os debates acadêmicos (MAGLIANO, 2007, p. 2).

Na literatura anterior aos estudos de gênero, que não observava as especificidades das condições sociais distintas entre homens e mulheres, os termos "autônomo" e "migração familiar" também davam suporte à teoria de que homens eram migrantes por excelência, enquanto as mulheres eram seguidoras passivas e não verdadeiras protagonistas do movimento (MOROKVASIC, 2014, p. 358). Em contrapartida, ao serem analisadas nos estudos migratórios a partir da perspectiva das relações de gênero e de como o gênero é um fator estruturante no processo migratório, as migrantes passaram a ser vistas como protagonistas (MOROKVASIC, 1984; BOYD; GRIECO, 2003; CASTRO, 2006; MAGLIANO, 2007). Junto ao aumento do número de mulheres nos movimentos migratórios e a influência do feminismo no meio acadêmico, a presença das migrantes ainda acarreta questões políticas relevantes, mais reivindicações por políticas sociais e serviços de assistência social (KOSMINSKY, 2007, p. 786).

Segundo Kosminsky, a perspectiva de gênero mostrou a partir do estudo aprofundado das instituições e ideologias como a vida familiar, o trabalho, as associações comunitárias, a locomoção das pessoas, inclusive os movimentos migratórios, são reforçados e desafiam o patriarcalismo. Além disso, tanto a incorporação da força de trabalho da mulher no contexto de industrialização dos países ocidentais (MOROKVASIC, 1984, p. 886), quanto a facilidade dos deslocamentos que propicia pessoas em condições desvantajosas, principalmente mulheres de países periféricos, busquem postos de 
trabalhos em outros países nas últimas décadas (SASSEN, 2010; LISBOA, 2007) demonstram um reforço à relação entre a segmentação do mercado e os papéis de gênero.

É comum que as migrantes ocupem postos de trabalhos no setor de limpeza, como faxineiras, e de cuidados com crianças, como babás. Esses postos de trabalho, inclusive, são usualmente relegados às migrantes por serem descartados pelos trabalhadores nacionais, o que contribui para a acentuar as baixas remunerações e condições precárias (BOYD; GRIECO, 2003, p. 24). A inserção das mulheres nesses setores informais da economia, como os serviços de cuidados, trabalhos domésticos e no mercado da prostituição, estão relacionadas à existência da herança cultural feminina e opressão de gênero (MOROKVASIĆ, 1984, p. 889). As relações de gênero estabelecidas a partir do ambiente familiar são ampliadas ao mercado de trabalho (MOROKVASIĆ, 1984, p. 889). Sendo assim, as tarefas e as ocupações desempenhados pelas mulheres, que foram sexualmente definidas, afetam suas experiências de migração, suas estratégias migratórias e seu potencial no mercado de trabalho (PERES, 2014, p. 150).

Nesse sentido:

É necessário pontuar, ainda, que o crescente fluxo migratório de mulheres para trabalhar como domésticas em países do Primeiro Mundo é consequência direta do desenvolvimento desigual promovido pelo capitalismo neoliberal. Reféns da histórica dominação e exploração colonial que se perpetua através da dominação oligárquica de suas elites, as pessoas e as famílias não conseguem sobreviver em seus países. Em função dos ajustes fiscais atribuídos pelo neoliberalismo aos países do Terceiro Mundo, o Estado tem se afastado de seus compromissos, tornando-se "mínimo para o social e máximo para o capital" (LISBOA, 2007, p. 808).

Nessa perspectiva, as normas sociais que regulam a vida das mulheres, estabelecidas a partir das relações de gênero, determinam os espaços adequados para elas (e também para os homens), as atividades 
que eles podem ou não realizar, o controle da sexualidade feminina e, no interior da família, operacionalizam-se as obrigações familiares e as estruturas de autoridade que afetam as formas e ritmos da migração feminina (CASTRO, 2006, p. 69). Logo, se as experiências migratórias de mulheres estão profundamente marcadas pelas diferenças de gênero, as redes de contato, a seletividade e as estratégias migratórias também se diferenciam de acordo com o gênero (PERES, 2014, p. 152). Observa-se que, junto a esse fator condicionante, as trajetórias migratórias das mulheres também estão relacionadas ao ciclo de suas vidas, sendo que o planejamento de suas vidas (tanto individual quanto familiar), e questões como o casamento e o nascimento de filhos são aspectos que orientam sua mobilidade (PERES, 2013, p. 125).

As diferenças significativas entre os sexos são diferenças de gênero. Cada sociedade dita o que espera de cada um dos sexos. O status sexual marca a participação de homens e mulheres nas instituições sociais, na família, na escola, na política, na economia, no Estado e nas religiões, que incluem valores e expectativas do que uma sociedade espera ser feminina ou masculino4 (CASTRO, 2006, p. 66$67)$.

Desse modo, a experiência migratória feminina está entrecortada pela própria condição social do que é ser mulher - e isso resvala também na forma como os lares de migrantes se estruturam. Em razão da necessidade econômica de trabalhar, há uma mudança na atribuição tradicional dos papéis de gênero. A migrante não está restrita à esfera da vida privada, mas também participa da esfera pública como trabalhadora. Isso gera mais autoestima às mulheres, promovendo-lhes

\footnotetext{
4 No original: "Las diferencias significativas entre los sexos son las diferencias de género. Cada sociedad dictamina qué espera de cada uno de los sexos. El status sexual marca la participación de hombres y mujeres en las instituciones sociales, en la familia, la escuela, la política, la economía, el Estado y en las religiones, las cuales incluyen valores y expectativas de lo que una sociedad espera del ser femenino o masculino". Cf. CASTRO, 2006, p.66-7.
} 
a oportunidade de participarem na tomada de decisão no ambiente familiar e na relação conjugal (PESSAR, 1984, p. 1192).

\section{Interseccionalidades e potencialidade de agência}

A experiência migratória tem múltiplos aspectos e está relacionada com uma heterogeneidade de fatores que perpassam a trajetória e que impactam a vida dos migrantes de formas variadas e ainda determinam a sua inserção no novo contexto social com possibilidades de transformação nas hierarquias e continuidades dos papéis de gênero (MAGLIANO, 2007, p. 5). Isso porque, como salienta a autora, a dimensão do gênero estrutura tanto a divisão do trabalho entre remunerado e produtivo ou não remunerado e reprodutivo quanto a divisão do trabalho produtivo em ocupações determinadas pela diferenciação sexual (MAGLIANO, 2007, p. 6).

A flexibilização e segmentação do mercado de trabalho produz postos de trabalho cada vez mais precários e informais, principalmente para trabalhadoras migrantes. Há tendência de concentração em atividades social e culturalmente definidas como "femininas", em setores relacionados ao trabalho reprodutivo, como os trabalhos domésticos e de cuidados. A condição da migrante é agravada por uma "discriminação tripla", composta pelo gênero, etnia e classe social, que se traduzem em uma participação laboral precária (MAGLIANO, 2007, p. 7).

Além da diferença de gênero, o potencial produtivo das migrantes está sempre restrito ao fato de serem trabalhadoras não nacionais (MOROKVASIĆ, 1984, p. 891), também por relações raciais, que estão presentes na compreensão social da raça: traços negros e indígenas, a cor da pele e outras características étnicas (PISCITELLI, 2008, p. 271). 
Nesse sentido, deve-se compreender que existem sistemas de opressão que estão fortemente presentes nas sociedades e que estabelecem as relações sociais e vão trazer implicações diversas às mulheres migrantes. As opressões de gênero, de raça e de classe, contextualizadas a partir das relações hegemônicas, são inseparáveis para se pensar a experiência migratória de mulheres. Nesse sentido, a experiência é marcada por diferentes categorias de articulação ou interseccionalidades (PISCITELLI, 2008, p. 264).

Apesar da abordagem ser utilizada para pensar sobre violações de direitos, Piscitelli (2008) esclarece que a formulação tem algumas fragilidades: por um lado, o fato de fundir a diferença com a desigualdade, destacando o impacto da estrutura sobre a identidade dos indivíduos e, por outro lado, o poder não é tratado como uma relação, mas como propriedade de um ou alguns indivíduos, reduzindo a capacidade de agência do indivíduo oprimido por variados sistemas (PISCITELLI, 2008, p. 267).

Na análise de Piscitelli (2008, p. 266), com base nesse debate das teóricas feministas, é preciso articular gênero com sexualidade, raça, classe, religião e nacionalidade, quando estamos observando a experiência de migrantes. Segundo a autora:

O debate sobre as interseccionalidades permite perceber a coexistência de diversas abordagens. Diferentes perspectivas utilizam os mesmos termos para referir-se à articulação entre diferenciações, mas elas variam em função de como são pensados diferença e poder. Essas abordagens divergem também em termos das margens de agência (agency) concedidas aos sujeitos, isto é, as possibilidades no que se refere à capacidade de agir, mediada cultural e socialmente (PISCITELLI, 2008, p. 267).

Com essa ideia da confluência que se dá na relação entre indivíduo e sociedade, a análise se volta ao contexto micro do cotidiano do indivíduo e, especialmente, ao âmbito da tomada de decisão, em concordância à reflexão de Boyd e Grieco (2003) sobre como as relações, 
papéis e hierarquias de gênero operam direta e distintamente na vida de homens e mulheres, de modo influenciar sua capacidade de agência sobretudo nos processos migratórios.

Como exposto anteriormente, na teoria de Amartya Sen, o desenvolvimento humano ocorre com a expansão das capacidades, as quais refletem a liberdade de agência de uma pessoa. A liberdade de agência se refere àquilo que a pessoa pode fazer e alcançar com relação ao que ela compreende como valioso ou ao que ela deseja (SEN, 1985, p. 203). E, na compreensão de Sen, a agência tem utilidade de acordo com aquilo que a pessoa julga importante, sendo ela um agente responsável por si, incluindo aquilo que a pessoa busca e escolhe. Ele compreende que a agência é um aspecto moral da vida e é importante para estimar o que uma pessoa pode fazer alinhado às suas concepções de que é bom (SEN, 1985, p. 206). Por isso, ele reitera:

A utilidade de uma pessoa não deve ser confundida com a valorização que ela mesma faz; assim, vincular o exercício de avaliação à utilidade da própria pessoa é muito diferente de julgar o sucesso de uma pessoa em termos da valorização que ela mesma faz. A distinção importante a fazer nesse contexto é a seguinte: uma pessoa pode não ter coragem de desejar uma grande mudança social, presa às circunstâncias em que vive, desde que tenha a oportunidade de avaliar a situação; contudo - o que caracteriza essencialmente um exercício político nesse contexto - , a pessoa pode valorizar uma mudança (SEN, 1993).

Nesse sentido, Sen analisa que tão importante quanto a agência, a liberdade de agir é significativa em sua abordagem. Isso porque, é relevante que a pessoa tenha capacidade de avaliar criticamente a situação em que está e, a partir disso, julgar por si, se deseja ou não permanecer dessa forma. Nesse sentido, a migração se mostra como um exercício de liberdade de agência da mulher, por um lado por ser protagonista da ação de migrar e, por outro, liberdade de escolha em migrar ou escolher para onde migrar, mesmo em condições limitadas. 
Em concordância a isso, a abordagem da interseccionalidade, em alguns estudos, não descarta a perspectiva da agência do sujeito, mas sim, busca por contribuir para a capacitação de grupos subordinados (PRINS, 2008, p. 280). Nesse sentido, Piscitelli (2008) observa que:

[...] os processos mediante os quais os indivíduos se tornam sujeitos não significam apenas que alguém será sujeito a um poder soberano, mas há algo mais, que oferece possibilidades para o sujeito. $\mathrm{E}$ os marcadores de identidade, como gênero, classe ou etnicidade não aparecem apenas como formas de categorização exclusivamente limitantes. Eles oferecem, simultaneamente, recursos que possibilitam a ação (PISCITELLI, 2008, p. 268).

Nessa perspectiva, a identidade não é percebida como título, mas como narrativas - não é sobre "o quê" uma pessoa é, mas sim, sobre "quem" ela é. Essa visão correlaciona o social e o indivíduo de como a história pessoal é criada pela própria pessoa em confluência com as possibilidades disponibilizadas pela sociedade: sendo assim, "somos simultaneamente menos ou mais que a soma das categorias sociais com as quais nos identificamos" (PRINS, 2008, p. 281). Assim, as adversidades e desigualdades enfrentadas pelas mulheres migrantes também podem ser recursos a sua agência.

Desse modo, é possível refletir sobre a proposta de Henning (2015) acerca da "agência interseccional". Mesmo que em meio à estrutura social que gera sistemas de opressão que se interseccionam, os indivíduos estão criando táticas de agência interseccional, na qual, os sujeitos utilizam das marcas criadas pelas opressões interseccionais (em si e nos outros) para "lidar com a criação, o questionamento e a desconstrução social de desigualdades" (HENNING, 2015, p. 117).

\section{Considerações finais}

A agência, segundo a teoria de Sen, é expressão da liberdade da pessoa frente ao que ela valoriza como importante para si mesma, bem 
como se caracteriza como um exercício político. Nesse sentido, é importante observar que a mulher no processo migratório, como sujeito protagonista do ato de migrar, está expandindo suas capacidades e, logo, avançando em desenvolvimento humano.

De modo geral, é importante observar que o processo migratório revela novas desigualdades a serem enfrentadas pelas mulheres, como a diferenciação a partir de sua nacionalidade e de sua etnia. Entretanto, é possível que a lógica da opressão seja subvertida em novas formas de negociar poder e novos arranjos sociais.

Nesse sentido, as diferenças, que pode ou não ser uma desigualdade, opressão e exploração, pode se mostrar como um igualitarismo, ou diversidade ou, até mesmo, formas democráticas de agência política, como indica Piscitelli (2008).

\section{Referências}

ARR, Sakiko Fukuda. Operacionalizando as ideias de Amartya Sen sobre capacidades, desenvolvimento, liberdade $e$ direitos humanos: o deslocamento do foco das políticas de abordagem do desenvolvimento. Disponível em: http:/ / sergiorosendo.pbworks.com/f/Fuuda-Parr+2002+Sen.pdf. Acesso em: 30 jan. 2020

BOYD, Monica; GRIECO, Elizabeth. Women and Migration: Incorporating Gender into International Migration Theory. Migration Policy Institute, março, 2003. Disponível em: https:/ / www.migrationpolicy.org/article/women-and-migrationincorporating-genderinternational-migration-theory. Acesso em: 20 abr. 2020.

CASTLES, Stephen; MILLER, Mark. Globalization, Development and Migration. In: CASTLES, Stephen; MILLER, Mark. The Age of Migration: International Population Movements in the Modern World. 4.ed. Londres: Palgrave Macmillan, 2009. 
CASTRO, J.Y.C. Ahora las mujeres se mandan solas: migración y relaciones de gênero em una comunidad mexicana transnacional llamada Pie de Gallo. 2006. Tese (Doutorado) - Universidad de Granada, 2006.

DE HAAS, Hein. Migration and development: a theoretical perspective. International Migration Review, v. 44, n. 1, 2010.

DE HAAS, Hein. Mobility and human development. IMI working paper 14. Oxford: International Migration Institute, University of Oxford. Disponível em: https://www.migrationinstitute.org/imiarchive/news/working-paper-14-now-publishedmobility-andhuman-development-hein-de-haas. Acesso em: 20 jul. 2019.

HENNING, Carlos Eduardo. Interseccionalidade e pensamento feminista: As contribuições históricas e os debates contemporâneos acerca do entrelaçamento de marcadores sociais da diferença. Revista Mediações, v. 20, n. 2, p. 97-128, jul./dez. 2015.

KOSMINSKY, Ethel V. Por uma etnografia feminista das migrações internacionais: dos estudos de aculturação para os estudos de aculturação para os estudos de gênero. Estudos Feministas, Florianópolis, n. 15, v. 3, set./ dez. 2007.

LEE, Everett S. A theory of Migration. Demography, v. 3, n. 1, p. 47-47, 1966.

LISBOA, Teresa Kleba. Fluxos migratórios de mulheres para o trabalho reprodutivo: a globalização da assistência. Estudos Feministas, Florianópolis, n. 15, v. 3, set./dez. 2007.

MAGLIANO, Maria José. Mujeres, migración y roles de género. El caso de la migración boliviana hacia Argentina. Anais da Jornadas Interescuelas/Departamentos de História, San Miguel de Tucumán: Universidad de Tucumán, 2007. Disponível em: http:/ / cdsa.aacademica.org/000-108/162. Acesso em: 10 jul. 2020.

MASSEY, Douglas S. et al. Social Structure, Household Strategies, and the Cumulative Causation of Migration. Population Index, v. 56, n. 1, p. 3-26, 1990.

MASSEY, Douglas S. et al. Worlds in Motion: Understanding International Migration at the end of the Millennium. New York: Oxford University Press, 2008. 
MOROKVASIĆ, Mirjana. "Birds of Passage Are Also Women...". The International Migration Review, v. 18, n. 4, p. 886-907, 1984.

MOROKVASIĆ, Mirjana. Gendering Migration. Migracijske i etničke teme /Migration and Ethnic Themes, v. 30, n. 3, p. 355-378, dez. 2014.

PERES, Roberta Guimarães. “O que importa é o que acontece com a sua família": um diálogo entre família e migração. Revista PerCursos. Florianópolis, v. 15, n. 28, p. 146-165, jan./jun. 2014.

PERES, Roberta Guimarães. Mulheres na fronteira: imigração e gênero. In: BAENINGER, Rosana (Org.). Migração internacional. Campinas: Núcleo de Estudos de População - Nepo/Unicamp, 2013.

PESSAR, P. R. The Linkage Between the household and workplace of dominican women in the U.S. International Migration Review, v. XVIII, n. $4,1984$.

PINHEIRO, Maurício Mota Saboya. As liberdades humanas como bases do desenvolvimento: uma análise conceitual da abordagem das capacidades humanas de Amartya Sen. Texto para discussão 1794. Brasília, Rio de Janeiro: IPEA, 2012.

PIORE, Michael J. Birds of Passage: Migrant Labor and Industrial Societies. Cambridge: University Press, 1979.

PISCITELLI, Adriana. Interseccionalidade, categorias de articulação e experiências de migrantes brasileiras. Sociedade e Cultura, v. 11, n. 2, p. 263-274, jul./dez. 2008.

PRINS, Baukje. Narrative accounts of origins: a Blind Spot in the Intersectional Approach? European Journal of Women's Studies, v. 13, n. 3, p. 277-290, 2006.

SANTOS, Mauro Augusto dos. BARBIERI, Alisson Flávio. CARVALHO, José Alberto Magno de. MACHADO, Carla Jorge. Migração: uma revisão sobre algumas das principais teorias. Texto para discussão Cedeplar-UFMG. Belo Horizonte: UFMG/Cedeplar, 2010. https://core.ac.uk/download/pdf/6314064.pdf. Acesso em: 30 out. 2019. 
SASSEN, Saskia. A criação de migrações internacionais. In: SASSEN, Saskia. Sociologia da Globalização. Tradução de Ronaldo Cataldo Costa. Porto Alegre: Editora ArtMed, 2010.

SASSEN, Saskia. The Global City: New York, London, Tokyo. Princeton University Press, 2001.

SASSEN, Saskia. The mobility of labor and capital: A study in international investment and labor flow. Cambridge University Press, 1990.

SEN, Amartya. Biographical. Nobelprize.org [online], 1998. Disponível em: $\quad$ https://www.nobelprize.org/prizes/economicsciences/1998/sen/biographical/. Acesso em: 20 jun. 2019.

SEN, Amartya. Desenvolvimento como Liberdade. Tradução de Laura Teixeira Motta. São Paulo: Companhia das Letras, 2000.

SEN, Amartya. O desenvolvimento como expansão de capacidades. Lua Nova, São Paulo, n. 28-29, p. 313-334, 1993.

SEN, Amartya. The standard of living (The Tanner lectures). Cambridge: Cambridge University Press, 1990. Disponível em: https:/ / tannerlectures.utah.edu/_documents/a-toz/s/sen86.pdf. Acesso em 07 jan. 2020.

SEN, Amartya. Well-Being, Agency and Freedom: The Dewey Lectures. The Journal of Philosophy, v. 82, n. 4, abr. 1985. 